\title{
The effect of load modelling on phase balancing in distribution networks using search harmony algorithm
}

\author{
Saeid Eftekhari, Mahmoud Oukati Sadegh \\ Department of Electrical and Electronic Engineering, University of Sistan and Baluchestan, Iran
}

\begin{tabular}{l}
\hline \hline Article Info \\
\hline Article history: \\
Received Apr 26, 2018 \\
Revised Dec 17, 2018 \\
Accepted Jan 2, 2019 \\
\hline
\end{tabular}

\section{Keywords:}

Distribution network

Harmony search algorithm

Load modelling

Phase balancing

Re-phasing

\begin{abstract}
Due to the unequal loads in phases and different customer consumption, the distribution network is unbalanced. Unbalancing in the distribution network, in addition to increasing power losses, causes unbalancing in voltages and increases operating costs. To reduce this unbalancing, various methods and algorithms have been presented. In most studies and even practical projects due to lack of information about the network loads, load models such as constant power model, constant current or constant impedance are used to model the loads. Due to the changing and nonlinear behaviours of today's loads, these models cannot show results in accordance with reality. This paper while introducing an optimal phase-balancing method, discusses the effect of load modelling on phase balancing studies. In this process the re-phasing method for balancing the network and the harmony search algorithm for optimizing the phase displacement process have been used. The simulation was carried out on an unbalanced distribution network of 25 buses. The results show well the effect of this comprehensive modelling on phase balancing studies. It also shows that in the re-phasing method for balancing the network and in the absence of a real load model, the use of which model offers the closest answer to optimal solutions.
\end{abstract}

Copyright (C) 2019 Institute of Advanced Engineering and Science. All rights reserved.

\section{Corresponding Author:}

Mahmoud Oukati Sadegh,

Department of Electrical and Electronic Engineering,

University of Sistan and Baluchestan, Zahedan, Iran.

Email: oukati@ece.usb.ac.ir

\section{INTRODUCTION}

Distribution networks are the largest part of the power systems. due to their lower voltage and higher current compared to the transmission section the share of losses in this section is much higher than the transmission systems. These losses impose huge costs on electricity distribution companies. Phase imbalances are one of the important factors in increasing the losses and creating problems in proper operation of distribution systems. So far, many studies have been conducted on the balancing of loads in distribution networks. A statistical estimation method that can detect the level, position, and unbalance of voltage in distribution networks is presented in [1]. In [2], the effects of voltage imbalance on induction motors are investigated. [3] has introduced and compared a number of imbalance indicators in the distribution network. In [4], the balancing problem in the distribution network is investigated using the combination of fuzzy logic and the Newton-Raphson method. In [5], using a voltage control equipment and other network components, an optimal load flow method has been proposed that can minimize the unbalanced voltage of the system. In [6], the reconfiguration method has been used to transfer loads from heavy load feeders to light loader feeders and to load balances in an unbalanced distribution network. In the reference [7], the authors have investigated the problem of phase balancing with several other objective functions in a weighted form using a genetic algorithm-based method. In [8], power electronics devices such as SVC to compensate for reactive power and in reference [9], fuzzy logic and hybrid optimization are used to balance the phases in distribution 
systems. The reference [10] has also examined the use of dispersed generation sources (their location and optimal size) in an unbalanced distribution network. One of the main methods of phase balancing is the re-phase method, which was first introduced in [11] as a mixed integer programming method. The need to increase the computational speed, especially in large networks, has caused the problem of re-phasing to be addressed using intelligent methods such as simulated annulling [12]. In [13], an innovative method called the Backtracking Search Method for the re-phasing problem is used to balance the distribution network. The authors in [14] designed an expert system to apply the re-phasing method for balancing phases in distribution systems. In [15], the authors compared several intelligent algorithms for the phase balancing problem and concluded that the dynamic programming algorithm performs better. In [16], the phase displacement method in radial and meshed distribution networks is applied using the BF-PSO algorithm. In reference [17], the immune algorithm is also proposed to balance the phases, taking into account the current imbalances.

Usually, in these papers, constant power, constant current, or constant impedance models are used for modelling of loads in phase balancing studies. Given the variable and non-linear behaviours of today's loads, these models for load in distribution network studies cannot show results in accordance with reality. Although these results are acceptable, they are not optimal. On the other hand, obtaining a precise load model in the grid is a very time consuming, complicated and costly one. Due to the fact that distribution companies are required to use a precise model for load modelling to conduct studies on the optimal use of power systems, including phase balancing studies, this paper studies the effect of different load modelling on the results of phase balancing. An unbalanced 25-basset network was used to conduct this study. Simulations carried out well illustrate and compare the effects of load modelling on phase balancing studies. First of all, a variety of load models are introduced in Section 2. Section 3 deals with the process of balancing using the re-phasing method. The load distribution method in unbalanced networks and the Harmony Search Optimization Method are presented in Sections 4 and 5, respectively. Section 6 presents the results and simulations, and finally, conclusions are given in Section 7.

\section{EXAMINING DIFFERENT LOAD MODELS}

There are two general models for estimating load parameters, the first model is a static load model, which is most commonly used for load flow problems and calculating the losses of lines and other networks in the steady state. The second model is known as the Dynamic Load Model, which is usually used to study the dynamics and stability of the network, and to regulate the relays, and all the cases that depend on the network and load dynamics in the transient state. In the long run, due to the fact that studies on phase balancing are carried out in steady state, we introduce the static model of load and its types.

\subsection{Static load model}

A model that expresses active and reactive power at any given time as a function of the amplitude and frequency of the voltage at the same time. Static load models are used for static load components, such as light and resistance loads, and also approximations for dynamic load components such as motor loads [18]. These models are divided into the following types.

\subsubsection{Constant power load model}

A static load model does not change the load power by changing the voltage range. Loads that have such features are known as constant power loads and form PQ buses. The characteristic of these loads is as follows:

$$
\mathrm{P}=\mathrm{P}_{0} \quad \mathrm{Q}=\mathrm{Q}_{0}
$$

\subsubsection{Constant current load modle}

A static load model in which the power is linearly and directly related to voltage. Loads with such characteristics are known as constant current loads. The characteristic of these loads is as follows:

$$
P \propto V \Rightarrow \frac{P}{V}=\text { cons } \Rightarrow \mathrm{I}=\text { cons }
$$

\subsubsection{Constant impedance load modle}

A static load model in which the load power is directly related to the voltage squared. The characteristic of these loads is as follows: 


$$
\begin{aligned}
& P \propto V^{2} \Rightarrow \frac{P}{V^{2}}=\mathrm{cons} \Rightarrow \frac{\mathrm{I}}{V}=\mathrm{cons} \\
& Q \propto V^{2} \Rightarrow \frac{Q}{V^{2}}=\mathrm{cons} \Rightarrow \frac{\mathrm{I}}{V}=\mathrm{cons}
\end{aligned}
$$

\subsubsection{Exponantial load modle}

In this load model, which is known as the exponential model, the active and reactive power function of the load varies in different views of the voltage, which is expressed in general terms:

$$
\begin{aligned}
& P=P_{\mathrm{o}}\left(\frac{V}{V_{\mathrm{o}}}\right)^{n_{P}} \\
& Q=Q_{\mathrm{o}}\left(\frac{V}{V_{\mathrm{o}}}\right)^{n_{q}}
\end{aligned}
$$

Vo, $P_{o}$ and $Q_{o}$ are the voltage, active and reactive power of the system respectively. $n_{p}$ and $n_{q}$, are the active and reactive components of the system, which indicate the degree of load-to-voltage dependence. Using this model, many loads can be modelled. Table 1 refers to sample values of $n_{p}$ and $n_{q}$ in several samples of loads.

Table 1. The Values of $n_{p}$ and $n_{q}$ for Different Load Models [18]

\begin{tabular}{ccccccc}
\hline $\begin{array}{c}\text { Constant } \\
\text { impedance }\end{array}$ & $\begin{array}{c}\text { Constant } \\
\text { current }\end{array}$ & $\begin{array}{c}\text { Constant } \\
\text { power }\end{array}$ & Industrial & Commercial & Residential & Load type \\
\hline 2 & 1 & 0 & 0.18 & 1.51 & 0.92 & $\mathrm{n}_{\mathrm{p}}$ \\
2 & 1 & 0 & 6 & 3.4 & 4.04 & $\mathrm{n}_{\mathrm{q}}$ \\
\hline
\end{tabular}

\section{BALANCING PROCESS}

In this paper, the rephasing method is used to perform phase balancing. In this method, a switch is considered for each bus, which can transfer the load from one phase to another. The general scheme of this approach is presented in Figure 1. There are six modes for the phases, each of which is assigned numbers 1-6. The status and phase change matrices for each mode are given in Table 2.

Table 2. Mode Number, Status, and Phase Shift Matrices for Each Switch

\begin{tabular}{rlrl}
\hline Phase & shift matrices & Status & Mode No. \\
$s_{1}$ & $=\left[\begin{array}{lll}1 & 0 & 0 \\
0 & 1 & 0 \\
0 & 0 & 1\end{array}\right]$ & $(\mathrm{ABC})$ & 1 \\
$s_{2}$ & $=\left[\begin{array}{lll}1 & 0 & 0 \\
0 & 0 & 1 \\
0 & 1 & 0\end{array}\right]$ & $(\mathrm{ACB})$ & 2 \\
$s_{3}$ & $=\left[\begin{array}{lll}0 & 1 & 0 \\
1 & 0 & 0 \\
0 & 0 & 1\end{array}\right]$ \\
$s_{4}$ & $=\left[\begin{array}{lll}0 & 1 & 0 \\
0 & 0 & 1 \\
1 & 0 & 0\end{array}\right]$ \\
$s_{5}$ & $=\left[\begin{array}{lll}0 & 0 & 1 \\
1 & 0 & 0 \\
0 & 1 & 0\end{array}\right]$ \\
$s_{6}$ & $=\left[\begin{array}{lll}0 & 0 & 1 \\
0 & 1 & 0 \\
1 & 0 & 0\end{array}\right]$ & & \\
\end{tabular}




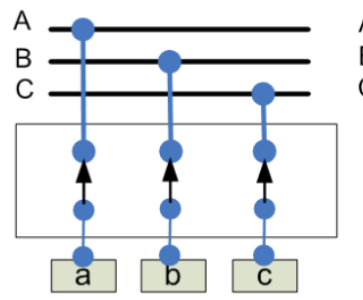

$(\mathrm{ABC})$

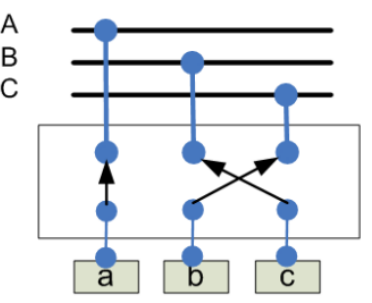

(ACB)

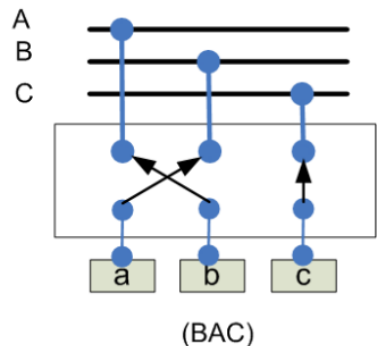

(BAC)

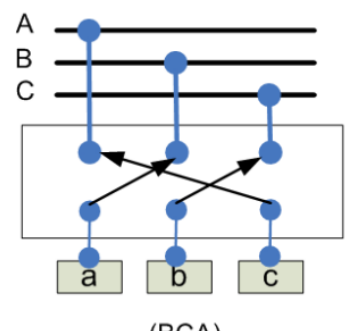

$(\mathrm{BCA})$

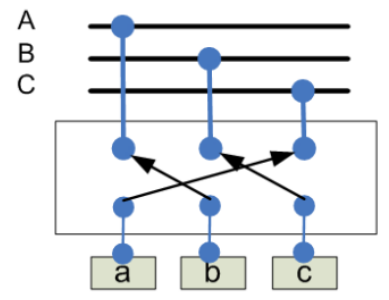

$(\mathrm{CAB})$

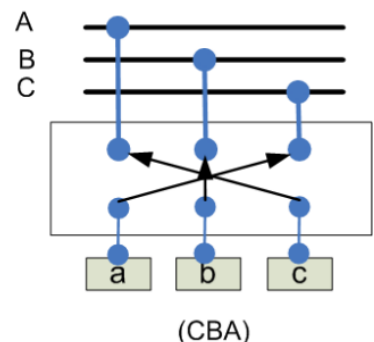

(CBA)

Figure 1. Six possible modes for re-phasing the phases

For a n-buses network, the vector $\mathrm{S}=[\mathrm{S} 1, \mathrm{~S} 2, \ldots \mathrm{Sn}]$ is defined as the key determinant of the state of the switches, for the purpose of phase displacement. Each member of this vector is identified by one of the modes 1 to 6. For example: $S=\left[\begin{array}{lllllll}3 & 1 & 1 & 1241234552254234154 & 1 & 1\end{array}\right]$. Can be an answer vector for a 25-bus network. The number 1 in the second element means that the phase arrangement in the second bus should be in the form $\mathrm{ABC}$ or the first mode, and the $s_{1}$ matrix is used to change the phase state. The number 3 in the ninth element requires the phase arrangement to be BAC or the third mode, and the $s_{3}$ matrix is used to change the phase state. So, for each bus, the following is used to convert the arrangement of phases (load displacement) from the initial state to the state specified in the vector $\mathrm{S}$ :

$$
\left[\begin{array}{l}
S_{A} \\
S_{B} \\
S_{C}
\end{array}\right]=S_{i}\left[\begin{array}{l}
S_{a} \\
S_{b} \\
S_{c}
\end{array}\right]
$$

Where the matrix si indicates the status of the switches in each bus and as mentioned in Table 2 it is called phase shift matrix. $\mathrm{I}_{0}, \mathrm{I}_{1}$ and $\mathrm{I}_{2}$ are the zero, positive and negative components of the current calculated from (6). The network unbalancing index can be obtained by using (7):

$$
\begin{aligned}
& {\left[\begin{array}{l}
\mathrm{I}_{0} \\
\mathrm{I}_{1} \\
\mathrm{I}_{2}
\end{array}\right]=\frac{1}{3}\left[\begin{array}{ccc}
\mathrm{I}_{\mathrm{a}} & \mathrm{I}_{\mathrm{b}} & \mathrm{I}_{\mathrm{c}} \\
\mathrm{I}_{\mathrm{a}} & \mathrm{aI}_{\mathrm{b}} & \mathrm{a}^{2} \mathrm{I}_{\mathrm{c}} \\
\mathrm{I}_{\mathrm{a}} & \mathrm{a}^{2} \mathrm{I}_{\mathrm{b}} & \mathrm{aI}_{\mathrm{c}}
\end{array}\right]} \\
& R M S I=\frac{\sqrt{\left|I_{0}\right|^{2}+\left|I_{2}\right|^{2}}}{\left|I_{1}\right|}
\end{aligned}
$$

In The above relations, $\mathrm{a}=\mathrm{e}^{\mathrm{j} 120}$. RMSI is calculated as an unbalancing index, and as the index is closer to zero, the network is less unbalanced [3]. 


\section{UNBALANCE NETWORK LOAD FLOW}

In this paper, a so-called backward forward sweep method [19] is used to carry out an unbalanced network load flow. The backward sweep is used to obtain the relationship between the branches current and the injection current of the buses, and the forward swept is used to calculate the buses voltage. The steps are as follows:

a. Calculate the bus injected current

$$
\left[\begin{array}{l}
I_{i a} \\
I_{i b} \\
I_{i c}
\end{array}\right]^{(k)}=\left[\begin{array}{l}
\left(S_{i a} / V_{i a}\right)^{*} \\
\left(S_{i b} / V_{i b}\right)^{*} \\
\left(S_{i c} / V_{i c}\right)^{*}
\end{array}\right]^{(k)}
$$

$I_{i}$, the injector current of the $i$-th bus to the load, $S_{i}$ is the apparent power in the $i$-th bus, and $v_{i}$ is the voltage of the $i$-th bus in $k$-th iteration.

b. Calculate the lines current (sweep back)

$$
\left[\begin{array}{l}
J_{l a} \\
J_{l b} \\
J_{l c}
\end{array}\right]^{(k)}=\left[\begin{array}{c}
I_{i a} \\
I_{i b} \\
I_{i c}
\end{array}\right]^{(k)}+\sum_{m \in M}\left[\begin{array}{c}
I_{m a} \\
I_{m b} \\
I_{m c}
\end{array}\right]^{(k)}
$$

In which $J_{l}$ shows the current flowing in $l$-th branch and $\mathrm{M}$ represent the set of lines that feed on the node $i$.

c. Calculating bus voltages (forward sweep)

$$
\left[\begin{array}{c}
V_{i a} \\
V_{i b} \\
V_{i c}
\end{array}\right]^{(k)}=\left[\begin{array}{c}
V_{j a} \\
V_{j b} \\
V_{j c}
\end{array}\right]^{(k)}-\left[\begin{array}{lll}
Z_{a a} & \mathrm{Z}_{\mathrm{ab}} & \mathrm{Z}_{\mathrm{ac}} \\
\mathrm{Z}_{\mathrm{ba}} & \mathrm{Z}_{\mathrm{bb}} & \mathrm{Z}_{\mathrm{bc}} \\
\mathrm{Z}_{\mathrm{ca}} & \mathrm{Z}_{\mathrm{cb}} & \mathrm{Z}_{\mathrm{cc}}
\end{array}\right]\left[\begin{array}{l}
J_{l a} \\
J_{l b} \\
J_{l c}
\end{array}\right]^{(k)}
$$

Where $Z_{a a}, Z_{b b}, Z_{c c}$ are self-impedance and $Z_{a b}, Z_{b c}, Z_{c a}$ are mutual impedances of the lines. The above steps will continue until the following convergence condition is reached:

$$
V_{i}^{(k)}-V_{i}^{(k-1)}<\varepsilon
$$

\section{HARMONY SEARCH (HS) ALGORITHM}

The Harmony Search Algorithm is a meta-heuristic algorithm developed in 2001 [20]. In this way, solving optimization problems is inspired from the process of playing simultaneously by the group of music orchestras. Due to low computation, simple concept, low parameters, easy implementation and applicability for discrete and continuous optimization problems, the Harmony Search algorithm has become one of the most used optimization algorithms in recent years in various issues. This algorithm can be used to solve various engineering problems due to less mathematical requirements than other meta-heuristic methods [21-22]. The parameters of the Harmony Search algorithm include Harmony Memory Size (HMS), Harmony Memory Consideration Rate (HMCR), Pitch Adjustment Rate (PAR) and Bandwidth (BW). Each Harmony is, in fact, a possible answer to the problem of optimization. The different steps of this algorithm are as follows:

a. Definition of optimization problem and initialization Parameters:

\section{Minimize $f(x)$}

Subject to $g(x) \geq 0$

In these relations, $f(x)$ is the objective function and $g(x)$ is the problem constraint. The parameters of HMS (Harmony Memory Size), HMCR (Harmony Memory Consideration Rate), PAR (Pitch Adjustment Rate) and BW (Bandwidth) are set at this stage.

The effect of load modelling on phase balancing in distribution networks using search... (Saeid Eftekhari) 
b. Initialize harmony memory:

At this point, the harmony memory is set to:

$$
H M=\left[\begin{array}{cccc}
X_{1}^{1} & \mathrm{X}_{2}^{1} & \ldots & \mathrm{X}_{N}^{1} \\
X_{1}^{2} & \mathrm{X}_{2}^{2} & \ldots & \mathrm{X}_{N}^{2} \\
\vdots & \vdots & \ldots & \vdots \\
X_{1}^{H M S} & \mathrm{X}_{2}^{H M S} & \ldots & \mathrm{X}_{N}^{H M S}
\end{array}\right]
$$

$H M S$ is the size of the harmony memory, or the number of harmony in memory, and $N$ is the number of variables for each harmony.

c. Create an improved new harmony:

First, $r_{1}, r_{2}$ and $r_{3}$ are assumed to be random numbers between zero and one. To generate a new harmonic vector, if $r_{l}$ is smaller than the HMCR value and the random value $r_{2}$ is greater than PAR, then:

$$
X_{\text {new }}(i)=X_{\text {old }}(i)
$$

If $r_{1}$ is smaller than HMCR and $r_{2}$ is smaller than PAR, then:

$$
X_{\text {new }}(i)=X_{\text {old }}(i)+r_{3} \times B W
$$

If $r_{l}$ is larger than $H M C R$, then for Xnew (i), a random value is considered within its permitted range.

d. Updating Harmony Memory:

In the process of updating the harmonic memory, if the harmonics or new harmonics are more competent than the worst harmonics in the memory, they replace it, otherwise they will be set aside.

e. Repeat steps 3 and 4 until the final condition is satisfied or repetitions end.

\section{SIMULATION RESULTS}

To perform the balancing process, a 25-bus test system is used, whose information is presented in [6]. The single-line diagram of this network is shown in Figure 2. The main bus voltage is considered to be $1.05 \mathrm{pu}$. Base apparent power and base voltage are $100 \mathrm{kVA}$ and $2.4 \mathrm{kV}$ respectively. The process of network balancing is done for different load models. The values of $n_{p}$ and $n_{q}$ for Exponential model are given in Table 3 and $V_{0}$ is $1 \mathrm{pu}$.

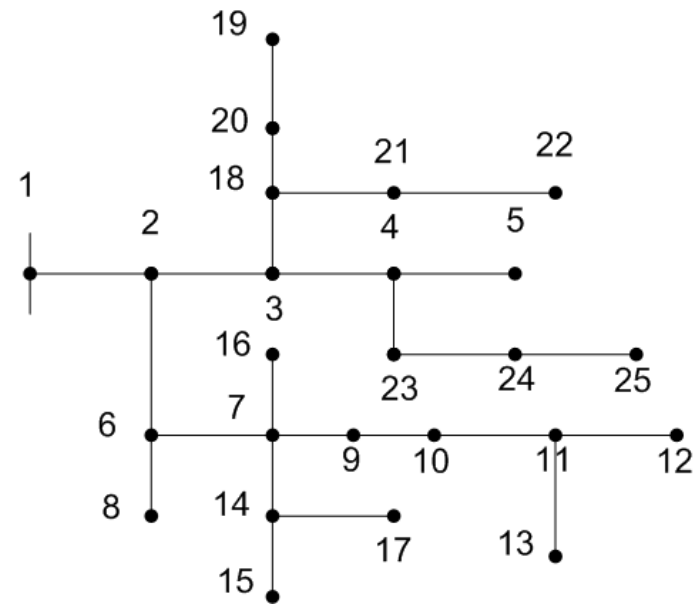

Figure 2. Unbalanced 25-bus network 
Table 3. The Values of $\mathrm{n}_{\mathrm{p}}$ and $\mathrm{n}_{\mathrm{q}}$ for Exponential Model

\begin{tabular}{|c|c|c|c|c|c|c|}
\hline Bus no & $\mathrm{n}_{\mathrm{p}}{ }^{\mathrm{a}}$ & $\mathrm{n}_{\mathrm{q}}{ }^{\mathrm{a}}$ & $\mathrm{n}_{\mathrm{p}}{ }^{\mathrm{b}}$ & $\mathrm{n}_{\mathrm{q}}{ }^{\mathrm{b}}$ & $\mathrm{n}_{\mathrm{p}}{ }^{\mathrm{c}}$ & $\mathrm{n}_{\mathrm{q}}{ }^{\mathrm{c}}$ \\
\hline 1 & 0.0000 & 0.0000 & 0.0000 & 0.0000 & 0.0000 & 0.0000 \\
\hline 2 & 0.0000 & 0.0000 & 0.0000 & 0.0000 & 0.0000 & 0.0000 \\
\hline 3 & 0.9200 & 4.0400 & 0.9200 & 4.0400 & 0.9200 & 4.0400 \\
\hline 4 & 0.9200 & 4.0400 & 0.9200 & 4.0400 & 0.9200 & 4.0400 \\
\hline 5 & 1.5100 & 3.4000 & 1.5100 & 3.4000 & 1.5100 & 3.4000 \\
\hline 6 & 1.5100 & 3.4000 & 0.1800 & 6.0000 & 0.9200 & 4.0400 \\
\hline 7 & 0.0000 & 0.0000 & 0.0000 & 0.0000 & 0.0000 & 0.0000 \\
\hline 8 & 0.1800 & 6.0000 & 0.1800 & 6.0000 & 0.1800 & 6.0000 \\
\hline 9 & 0.1800 & 6.0000 & 0.1800 & 6.0000 & 0.1800 & 6.0000 \\
\hline 10 & 0.9200 & 4.0400 & 0.9200 & 4.0400 & 0.9200 & 4.0400 \\
\hline 11 & 0.1800 & 6.0000 & 0.1800 & 6.0000 & 0.1800 & 6.0000 \\
\hline 12 & 0.1800 & 6.0000 & 0.1800 & 6.0000 & 0.1800 & 6.0000 \\
\hline 13 & 0.9200 & 4.0400 & 0.9200 & 4.0400 & 0.9200 & 4.0400 \\
\hline 14 & 0.1800 & 6.0000 & 0.1800 & 6.0000 & 0.1800 & 6.0000 \\
\hline 15 & 0.9200 & 4.0400 & 0.9200 & 4.0400 & 0.9200 & 4.0400 \\
\hline 16 & 1.5100 & 3.4000 & 1.5100 & 3.4000 & 1.5100 & 3.4000 \\
\hline 17 & 1.5100 & 3.4000 & 1.5100 & 3.4000 & 1.5100 & 3.4000 \\
\hline 18 & 1.5100 & 3.4000 & 1.5100 & 3.4000 & 1.5100 & 3.4000 \\
\hline 19 & 0.1800 & 6.0000 & 0.1800 & 6.0000 & 0.1800 & 6.0000 \\
\hline 20 & 0.9200 & 4.0400 & 0.9200 & 4.0400 & 0.9200 & 4.0400 \\
\hline 21 & 1.5100 & 3.4000 & 1.5100 & 3.4000 & 1.5100 & 3.4000 \\
\hline 22 & 0.1800 & 6.0000 & 0.1800 & 6.0000 & 0.1800 & 6.0000 \\
\hline 23 & 0.9200 & 4.0400 & 0.9200 & 4.0400 & 0.9200 & 4.0400 \\
\hline 24 & 0.9200 & 4.0400 & 0.9200 & 4.0400 & 0.9200 & 4.0400 \\
\hline 25 & 0.9200 & 4.0400 & 0.9200 & 4.0400 & 0.9200 & 4.0400 \\
\hline
\end{tabular}

\subsection{Network load balancing}

In this network, the nominal capacity of the main bus transformer is $1100 \mathrm{kVA}$ for each phase. $S_{a}$ represents the apparent power output of each phase of the main bus transformer. Because of the imbalance of the phases, the load of the main bus transformer between the phases is not the same. For example, phase has been loaded more than existing capacity and other phases less than the available capacity. The process of balancing phases is performed in different load models. These models include constant power, constant current, constant impedance and mixed (industrial, commercial, household) model. After balancing, it is observed that the main bus transformer capacities of the phases are more balanced. $S_{\text {margin }}$ is the difference in nominal capacity of each phase of the transformer and the apparent power output of each phase $\left(S_{\text {margin }}=1100-S_{a}\right)$. According to the results of Table 4, before balancing, this value is negative for the A phase, which indicates that phase A is loaded more than the limit. For other phases, this value is positive, which indicates that the maximum capacity of those phases is not used. After the balancing process, as shown in Table 4, the values of $S_{a}$ are fairly equal in each phase. As a result, $S_{\text {margin }}$ is fairly equal in different phases. These values are given for various models in Table 4. For example, in the case where the loads are modelled as constant power, the $S_{a}$ is $972 \mathrm{kV}$, for constant current load model is $987 \mathrm{kV}$, for constant impedance load model is $1002 \mathrm{kV}$, and for mixed model (so called Exponential model) is $1004 \mathrm{kV}$.

Table 4. The Capacity of Each Transformer Phase before and After Balancing for Different Load Models

\begin{tabular}{cccccccc}
\hline C phase & $\begin{array}{c}\text { B phase } \\
\text { After balancing }\end{array}$ & A phase & C phase $\begin{array}{c}\text { B phase } \\
\text { Before balancing }\end{array}$ & A phase & Parameter & Load model \\
\hline 971.97 & 972.74 & 972.85 & 990 & 734 & 1197 & $\mathrm{~S}_{\mathrm{a}}(\mathrm{kVA})$ & Constant power \\
128.03 & 127.26 & 127.15 & 109 & 365 & -97 & $\mathrm{~S}_{\operatorname{margin}}(\mathrm{kVA})$ & \\
988.7 & 987.05 & 987.3 & 1006 & 753 & 1204 & $\mathrm{~S}_{\mathrm{a}}(\mathrm{kVA})$ & Constant current \\
111.3 & 112.95 & 112.7 & 93 & 346 & -104 & $\mathrm{~S}_{\text {margin }}(\mathrm{kVA})$ & \\
1001.3 & 1002.2 & 1002.8 & 1020 & 770 & 1210 & $\mathrm{~S}_{\mathrm{a}}(\mathrm{kVA})$ & Constant impedance \\
98.73 & 97.81 & 97.2 & 79 & 329 & -110 & $\mathrm{~S}_{\operatorname{margin}}(\mathrm{kVA})$ & \\
1003.3 & 1004.8 & 1005 & 1032 & 766 & 1212 & $\mathrm{~S}_{\mathrm{a}}(\mathrm{kVA})$ & \multirow{2}{*}{ Mixed(Exponential model) } \\
96.17 & 95.19 & 94.95 & 76 & 325 & -112 & $\mathrm{~S}_{\text {margin }}(\mathrm{kVA})$ & \\
\hline
\end{tabular}

The effect of load modelling on phase balancing in distribution networks using search ... (Saeid Eftekhari) 


\subsection{Voltage balancing}

The unbalancing in voltage at each bus is defined as:

$$
\delta V_{\max }=\max \left(|V|_{a, b, c}\right)-\min \left(|V|_{a, b, c}\right)
$$

Studies show that $\delta V_{\max }$ is high for all buses for all four load models. In all load models, the maximum unbalancing in voltage $\left(\max \left(\delta V_{\max }\right)\right)$ is significant before balancing. After balancing, this unbalancing in voltage is noticeably reduced. For the constant power model, as shown in Table 4, the maximum unbalancing in voltage is equal to 0.0266 , which is reduced to 0.0068 after balancing. Similarly, in other models, the maximum unbalancing in voltage after the balancing is significantly reduced.

According to Table 5, the maximum unbalancing in voltage has dropped from 0.0256 to 0.0083 for constant current load model and from 0.0246 to 0.0096 for constant impedance load model. This amount has decreased for the mixed model (industrial, commercial, residential) from 0.0243 to 0.0074 .

Table 5. Unbalancing in Voltage for Different Load Models Before and After Balancing

\begin{tabular}{ccc}
\hline $\begin{array}{c}\text { After balancing } \\
\max \left(\delta \mathrm{V}_{\max }\right)\end{array}$ & $\begin{array}{c}\text { Before balancing } \\
\max \left(\delta \mathrm{V}_{\max }\right)\end{array}$ & Load model \\
\hline 0.0068 & 0.0266 & Constant power \\
0.0083 & 0.0256 & Constant current \\
0.0096 & 0.0246 & Constant impedance \\
0.0074 & 0.0243 & Mixed \\
\hline
\end{tabular}

\subsection{Network unbalancing index}

Table 6 shows the values of the zero, positive and negative components of the current as well as the network unbalancing index (RMSI) for different load models before and after balancing. Before balancing the index of network unbalancing, as well as the values of negative and zero components of the current, are high, but after balancing these values have been significantly reduced. For constant power model, the components of zero and negative before balancing are equal to 1.281 and 1.274 , which are significant values. In this case, the RMSI index is 0.1947 . After balancing, the current zero and negative components were 0.0022 and 0.0055 respectively. Also, the RMSI has decreased to 0.0006 . Results for other models are shown in Table 6.

Table 6. Current Components and RMSI for Different Load Models Before and After Balancing

\begin{tabular}{ccccccccc}
\hline & \multicolumn{3}{c}{ After balancing } & \multicolumn{3}{c}{ Before balancing } & Load model \\
\hline RMSI & $\mathrm{I}_{2}$ & $\mathrm{I}_{1}$ & $\mathrm{I}_{0}$ & RMSI & $\mathrm{I}_{2}$ & $\mathrm{I}_{1}$ & $\mathrm{I}_{0}$ & Constant power \\
0.0006 & 0.0055 & 9.26 & 0.0022 & 0.194 & 1.27 & 9.27 & 1.28 & Constant current \\
0.0012 & 0.011 & 9.40 & 0.0020 & 0.187 & 1.24 & 9.40 & 1.24 & Constant impedance \\
0.0014 & 0.0055 & 9.54 & 0.0139 & 0.180 & 1.21 & 9.53 & 1.21 & Mixed \\
\hline
\end{tabular}

\subsection{Network losses}

Table 7 shows the system losses before and after balancing. As can be seen, network losses after balancing have been reduced for all load models, but this is not the same for all models. For a constant power load model, the losses before the balancing are $68.483 \mathrm{kWh}$, which is reduced to $65.81 \mathrm{~kW}$ after balancing. In the constant current model, the losses before and after the balancing are 70.04 and $67.92 \mathrm{~kW}$, respectively. For impedance load model, the network losses are equal to $71.32 \mathrm{~kW}$, which after balancing is equal to 69.49 $\mathrm{kW}$. Finally, in the mixed model (industrial, commercial, household) this amount has decreased from $71.5 \mathrm{~kW}$ to $69.44 \mathrm{~kW}$.

Table 7. System Losses Before and After Balancing for Different Models

\begin{tabular}{ccc}
\hline $\begin{array}{c}\text { After balancing } \\
\text { PLOSS }(\mathrm{kw})\end{array}$ & $\begin{array}{c}\text { Before balancing } \\
\text { PLOSS }(\mathrm{kw})\end{array}$ & Load model \\
\hline 65.81 & 68.483 & Constant power \\
67.92 & 70.01 & Constant current \\
69.49 & 71.32 & Constant impedance \\
69.44 & 71.50 & Mixed \\
\hline
\end{tabular}




\subsection{The current of phases}

The flow of phases before and after balancing is given in Table 8. Before balancing, the difference between the currents in the phases is relatively high. Because the loading on the A phase is greater, therefore, a greater current is drawn and, due to lower loading in phase B, the current of this phase is lower. After performing the balancing process, it is observed that the currents of the phases are more balanced, meaning that the currents in the three phases are fairly uniform.

Before balancing and in the constant power load model, the current in A phase is 11.36, in B phase is 6.99 and in $\mathrm{C}$ phase is 9.39. After balancing, the A phase current is equal to 9.2652, the B phase current is equal to 9.2642 and the $\mathrm{C}$ phase current is equal to 9.257 .

Also, in the constant current load model and before balancing, the currents in the phases $\mathrm{A}, \mathrm{B}$ and $\mathrm{C}$ are 11.46, 7.17 and 9.58, respectively. After balancing the A phase current is 9.4, the B phase current is 9.41 and the $\mathrm{C}$ phase current is 9.38 . The values are in pu.

Table 8. Phase Currents Before and After Balancing

\begin{tabular}{ccccccc}
\hline \multicolumn{3}{c}{ After balancing } & \multicolumn{3}{c}{ Before balancing } & Load model \\
$\mathrm{I}_{\mathrm{c}}(\mathrm{pu})$ & $\mathrm{I}_{\mathrm{b}}(\mathrm{pu})$ & $\mathrm{I}_{\mathrm{a}}(\mathrm{pu})$ & $\mathrm{I}_{\mathrm{c}}(\mathrm{pu})$ & $\mathrm{I}_{\mathrm{b}}(\mathrm{pu})$ & $\mathrm{I}_{\mathrm{a}}(\mathrm{pu})$ & Constant power \\
\hline 9.257 & 9.2642 & 9.2652 & 9.43 & 6.99 & 11.40 & Constant current \\
9.38 & 9.41 & 9.40 & 9.58 & 7.17 & 11.46 & Constant impedance \\
9.55 & 9.52 & 9.54 & 9.72 & 7.34 & 11.53 & Mixed \\
9.56 & 9.57 & 9.56 & 9.83 & 7.30 & 1154 & \\
\hline
\end{tabular}

\subsection{Validation of the proposed method for phase balancing}

In order to validate the proposed method, in Table 9, the results of this paper are compared with the results of reference [23], which is one of the most recent researches in this field. In the reference [23], the current injection load flow method, the constant power load model, and the PSO algorithm are used to carry out the balancing process. With reference to the fact that the results of reference [23] are obtained using the constant power load model, only the results obtained from the constant power load model in the proposed method of this paper are compared with the results of reference [23]. Significant reduction of zero and negative component currents as well as network unbalancing index (RMSI) in the proposed method is evident in comparison with the results obtained from reference [23].

Table 9. Comparing the Results of the Harmonic Search Algorithm with the Reference [23]

\begin{tabular}{ccccc}
\hline RMSI & $\mathrm{I}_{2}(\mathrm{pu})$ & $\mathrm{I}_{2}(\mathrm{pu})$ & $\mathrm{P}_{\text {loss }}(\mathrm{kw})$ & \\
\hline 0.194 & 1.27 & 1.28 & 68.48 & Initial condition \\
0.0032 & 0.026 & 0.013 & 65.86 & Jsing the reference[23]method \\
0.0006 & 0.005 & 0.0022 & 65.81 & Proposed method \\
\hline
\end{tabular}

\subsection{The effect of load modelling on the results of balancing}

As stated above, on each bus there is a switch that has 6 states, which can have states 1 to 6 . The status of the switches in the six positions is expressed in Figure 1. The status of these switches before and after balancing for the 25-bus network is given in Table 10. It is noted that changing the load model changes the status of the system switches.

Table 10. The Status of the 25-bus Switches Before and After Balancing

\begin{tabular}{|c|c|}
\hline Switches status & Load model \\
\hline 1111111111111111111111111 & Initial status (before balancing) \\
\hline 1143112511313121551121136 & Constant power \\
\hline 1132436133436566243644665 & Constant current \\
\hline 1121314235213121341564263 & Constant impedance \\
\hline 1135421321343121363144113 & Mixed \\
\hline
\end{tabular}

The above results show well that changing the load model yields different results in balancing studies. Since the distribution network loads are a combination of industrial, commercial, and residential loads, and the acquisition of components of these loads is difficult and time consuming, in many cases, studies of distribution networks, are carried out using constant power load model. Certainly, in such cases, the results cannot be optimized. It is further examined that, in balancing studies if an unbalanced network is 
composed of different loads, and actual load model is not available then how much the results obtained by using constant power, constant current, or constant impedance models will different with actual or optimal results?

For this purpose, the arrangement of the switches obtained from the constant power, constant current, and constant impedance load model is used in the network with mixed load and the results are compared with the optimum state obtained from the consideration of the mixed load model. The results of this comparison can be seen in Table 11. According to the results, the losses are almost equal, but other parameters are different. For example, the RMSI value in a mixed-load network, using the arrangement of the switches obtained from the constant power load model, is equal to 0.0033 . However, using the arrangement of the switches obtained from constant current or constant impedance model, this parameter is 0.0145 and 0.0133 respectively.

As can be seen in the Table 11, when the arrangement of the switches obtained from the constant power model is used in the mixed- load network, the results are closer to the optimum results. This applies to three-phase currents as well as balanced distribution of three-phase power.

Table 11. Comparison of the Results of using the Arrangement of Switches Obtained from Different Load Models in Grid

\begin{tabular}{|c|c|c|c|c|c|c|c|c|}
\hline RMSI & $\mathrm{I}_{\mathrm{a}}$ & $\mathrm{I}_{\mathrm{b}}$ & $\mathrm{I}_{\mathrm{c}}$ & $\begin{array}{c}\text { Losses } \\
(\mathrm{kw})\end{array}$ & C phase & $\begin{array}{c}\mathrm{S}_{\text {margin }}(\mathrm{kVA}) \\
\mathrm{B} \text { phase }\end{array}$ & A phase & \\
\hline 0.0033 & 9.5851 & 9.555 & 9.558 & 69.493 & 96.40 & 96.66 & 93.56 & $\begin{array}{c}\text { Grid with the arrangement of the } \\
\text { switches obtained from the constant } \\
\text { power }\end{array}$ \\
\hline 0.0145 & 9.4018 & 9.62 & 9.69 & 69.621 & 82.511 & 89.582 & 112.81 & $\begin{array}{c}\text { Grid with the arrangement of the } \\
\text { switches obtained from the constant } \\
\text { current }\end{array}$ \\
\hline 0.0133 & 9.5093 & 9.4686 & 9.7229 & 69.524 & 79.094 & 105.79 & 101.52 & $\begin{array}{l}\text { Grid with the arrangement of the } \\
\text { switches obtained from the constant } \\
\text { impedance }\end{array}$ \\
\hline 0.0014 & 9.56 & 9.57 & 9.56 & 69.422 & 96.17 & 95.19 & 94.95 & $\begin{array}{c}\text { Grid with the arrangement of the } \\
\text { switches obtained from the mixed load } \\
\text { model(optimum state) }\end{array}$ \\
\hline
\end{tabular}

\section{CONCLUSIONS}

In this research, rephasing method was used to balance the network, as well as the harmony search algorithm due to its simplicity, efficiency, and less mathematical considerations to optimize the phase displacement process. The results compared with the recent studies indicate the effectiveness of the proposed method. Due to the importance of load modelling in the networks, the effect of different load models on the network balancing process was investigated. Constant power, constant current, constant impedance and mixed model (industrial, residential, commercial) were used to model the loads in distribution system. The results show that if different models are used, the results will be significantly different. This suggests that in order to obtain optimal solutions, exact modelling of loads is required in network studies, including balancing studies. Since obtaining a precise load model in the distribution network requires extensive studies and accurate measurements, and most distribution companies and network operators lack the above information, it is important to identify the appropriate model to find solutions that are close to optimal solutions. The results of this paper show that the use of a constant power model for displaying loads offers more accurate answers to optimal solutions.

\section{REFERENCES}

[1]. N. Woolley and J. Milanovic, "Statistical Estimation of the Source and Level of Voltage Unbalance in Distribution Networks," IEEE Transactions on Power Delivery, vol. 27, no. 3, pp. 1450-1460, 2012.

[2]. L. Youb, "Effects of Unbalanced Voltage on the Steady State of the Induction Motors," International Journal of Electrical Energy, vol. 2, no. 1, 2014.

[3]. M. Bina and A. Kashefi, "Three-phase unbalance of distribution systems: Complementary analysis and experimental case study," International Journal of Electrical Power \& Energy Systems, vol. 33, no. 4, pp. 817-826, 2011.

[4]. W. M. Siti, A. Jimoh, and D. Nicolae, "Distribution network phase load balancing as a combinatorial optimization problem using fuzzy logic and Newton-Raphson," Electr. Power Syst. Res, vol. 81, pp. 1079-1087, 2011. 
[5]. L. R. Araujo, D. R. R. Penido ,S. Carneiro, and J. L. R. Pereira, "A Three-Phase Optimal Power-Flow Algorithm to Mitigate Voltage Unbalance," IEEE Trans. Power Del, vol. 28, no. 4, pp. 2394 - 2402, 2013.

[6]. G. Vulasala, S. Sirigiri, and R. Thiruveedula, "Feeder Reconfiguration for Loss Reduction in Unbalanced Distribution System Using Genetic Algorithm," International Journal of Computer, Electrical, Automation, Control and Information Engineering, vol. 3, no. 4, 2009.

[7]. T.-H. Chen and J.-T. Cherng, "Optimal Phase Arrangement of Distribution Transformers Connected to a Primary Feeder for System Unbalance Improvement and Loss Reduction Using a Genetic Algorithm," IEEE Trans. Power Syst, vol. 15, no. 3, pp. 994 - 1000, 2000.

[8]. F. R. Quintela, J. M. G. Arévalo, R. C. Redondo, and N .R. Melchor, "Four-wire three-phase load balancing with Static VAr Compensators," Elect. Power Energy Syst, vol. 33, pp. 562-568, 2011.

[9]. A. Ukil and W. Siti, "Feeder load balancing using fuzzy logic and combinatorial optimization-based implementation," Electr. Power Syst. Res, vol. 78, pp. 1922-1932, 2008.

[10]. Ishan Gupta and V. Gupta, "Unbalanced Radial Distribution System Load Flow and Voltage Profile Enhancement in the presence of Distributed Generators," International Journal of Engineering Research \& Technology, vol. 4, no. 5, 2015.

[11]. J. Zhu, M.-Y. Chow, and F. Zhang, "Phase Balancing using Mixed-Integer Programming," IEEE Trans. Power Syst, vol. 13, no. 4, pp. 1487 - 1492, 1998.

[12]. G. B. J. Zhu, M. Chow, "Phase Balancing using Simulated Annealing," IEEE Trans. Power Syst, vol. 14, no. 4, pp. $1508-1513,1999$.

[13]. C.-H. Lin, C.-S. Chen, and H.-J. Chuang, "Heuristic Rule-Based Phase Balancing of Distribution Systems by Considering Customer Load Patterns," IEEE Trans. Power Syst, vol. 20, no. 2, pp. 709 - 716, 2005.

[14]. C.-H. Lin, C.-S. Chen, and H.-J. Chuang, "An Expert System for Three Phase Balancing of Distribution Feeders," IEEE Trans. Power Syst, vol. 23, no. 3, pp. 1488 - 1496, 2008.

[15]. K. Wanga, S. Skienab, and T. G. Robertazzia, "Phase balancing algorithms," Electr. Power Syst. Res, vol. 96, pp. $218-224,2013$.

[16]. R. A. Hooshmand and S. Soltani, "Fuzzy Optimal Phase Balancing of Radial and Meshed Distribution Networks Using BF-PSO Algorithm," IEEE Trans. Power Syst, vol. 27, no. 12, pp. 47 - 57, 2012.

[17]. M. Y. Huang, C. S. Chen, C. H. Lin, and M. S. Kang, "Three-phase balancing of distribution feeders using immune algorithm," IET Generation, Transmission \& Distribution, vol. 2, no. 3, pp. 383-392, 2008.

[18]. "Load Representation for Dynamic Performance Analysis," IEEE Trans Power Syst, vol. 8, no. 2, pp. 472 - 482, 1993.

[19]. K. K. Murthy and S. V. J. R. Kumar, "Three-Phase Unbalanced Radial Distribution Load Flow Method," International Refereed Journal of Engineering and Science, vol. 1, no. 1, 2012.

[20]. Z. W. Geem, J. H. Kim, and G. V. Loganathan, "A new heuristic optimization algorithm: harmony search," $S A G E$ Publications, vol. 76, no. 2, pp. 60-68, 2001.

[21]. Ali, M., Praveen S. Babu and B. Gurusekhar. "Reconfiguration with simultaneous DG installation to improve the Voltage Profile in Distribution Network using Harmony Search Algorithm," Bulletin of Electrical Engineering and Informatics, Vol. 4, No. 4, pp. 257 273, December 2015.

[22]. Devabalaji K.R, Ravi K. "Optimal Placement and sizing of capacitor in Radial Distribution System using Harmony Search Algorithm," Proceeding of International Conference on Electrical Engineering, Computer Science and Informatics (EECSI 2014), Yogyakarta, Indonesia, 20-21 August 2014

[23]. D. Singh, R. K. Misra, and S. Mishra, "Distribution system feeder re-phasing considering voltage-dependency of loads," Elect. Power Energy Syst, vol. 76, pp. 107-119, March 2016.

\section{BIOGRAPHIES OF AUTHORS}

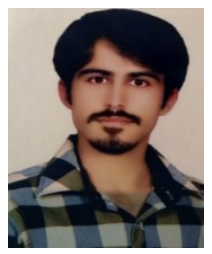

Saeid Eftekhari was born in 1991 in Deh Dasht, Iran. He received the B.Sc. and M.Sc. degree in electrical power system engineering from Esfahan University, Esfahan, Iran, in 2014 and University of Sistan and Baluchestan, Zahedan, Iran in 2017 respectively. His research interests are Electrical distribution system and Smart grid.

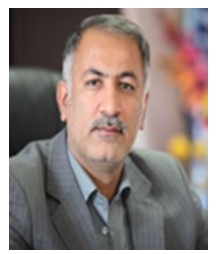

Mahmoud Oukati Sadegh was born in 1966 in Zabol, Iran. He received the B.Sc. and M.Sc. degree in electrical power system engineering from Tehran University, Tehran, Iran, in 1989 and 1992 respectively. the Ph.D. degree in electrical engineering from Strathclyde University in Glasgow, UK in 2003. Currently, he is an Assistant Professor in the Department of Electrical and Electronic Engineering, University of Sistan and Baluchestan, Zahedan, Iran. His research interests are power system control and operation, Electrical distribution system and Smart grid. 